\title{
PREVENTION, EDUCATION AND TRANSFORMATION VERSUS RESOLUTION
}

\author{
A.M. Sousa Neves Vieira, R. Neves Vieira \\ CICS.NOVA.IPLeiria e ESECS.IPLeiria (PORTUGAL)
}

\begin{abstract}
When we refer to mediation as an area and set of competences which are transversal to various professions, and as a hermeneutical philosophy, we assume the interpersonal and intercultural communication as a systematic interpretation of interests of the parties in an interaction and as the will of those involved.

In the mediation between different cultural values, the educator and social workers emerge as mediators between social groups and the most diverse public and private institutions, relying on a multi-topical hermeneutics for the realisation of the rights and interests of the groups and subjects involved in the interaction.
\end{abstract}

The purpose of the mediation process is to seek the autonomy of these groups and people, known today as empowerment.

If education should be an instrument to promote equal opportunities and an instrument to favour social justice, school should become a fundamental space to legitimize and strengthen values which structure the State which is, however, nowadays increasingly multicultural. In this sense school has to seek forms of intercultural translation as it not only reconstructs cognitive systems but also operates at the level of personal and group identity processes.

So, prevention, education and transformation versus resolution is a very important way to promote the empowerment of minorities.

The main objective of this text is of an essayistic and pedagogical nature, trying to show, using examples of social workers and social educators who work with teachers in Portuguese schools, other ways of socio-educational intervention besides the action at the end of the line, at the end of the process. The main idea is to underline the importance of education as a process of (trans) formations throughout individual and social life trajectories, seeking autonomy, underlining the importance of prevention versus intervention that many ignore as fundamental for social and educational transformation, which implies thinking not from the social and educational problems and how to solve them, but, on the contrary, educating for its avoidance, educating for citizenship, for the social values how to live together and for an ethics of welcoming and intercultural coexistence.

In terms of some results, Social Workers have, according to our study, more resolving concerns; Social Educators seem to be more concerned with a dialogical, mediating, empowering and preventive intervention and finally, therefore more transformative than properly resolving.

Keywords: Education, prevention, resolution, mediation, empowerment.

\section{INTRODUCTION}

Any translation implies going back and forth between meanings of different linguistic-cultural margins. In a first approach, we may say that to mediate is to interpret, in its anthropological sense. Mediation is, therefore, a strategy of building bridges and crossings between people, different points of view and cultural boundaries. We are not, therefore, giving privilege to the mediation techniques associated to the classic mediation which will be discussed further on.

It is common to hear about family mediation, sociocultural mediation, conflict mediation, insurance mediation, labour mediation, intercultural mediation, among others.

The educational mediation, school and socio-pedagogic mediation are also concepts which are increasingly conveyed by educational professionals and in the objectives of some educational projects ([1], [2], among others). 
When we refer to mediation as an area and set of competences which are transversal to various professions, and as a hermeneutical philosophy, we assume the interpersonal and intercultural communication ([3], [4], [5]) as a systematic interpretation of interests of the parties in an interaction and as the will of those involved. In the mediation between different cultural values, the social worker and the educator emerge as mediators between social groups and the most diverse public and private institutions, relying on a multi-topical hermeneutics ([6]) for the realisation of the rights and interests of the groups and subjects involved in the interaction. The purpose of the mediation process is to seek the autonomy of these groups and people, known today as empowerment ([7]).

\section{METHODOLOGY}

In this essay, which is not the presentation of the empirical study carried out, the distinction between a more resolutive intervention versus a more socio-educational, preventive, empowering and transformative intervention, was made using the observation of practices and the collection of narratives from social workers and social educators working in a multidisciplinary team at a school in central Portugal.

We have now re-read the data collected in a research work carried out in this school, where for several years there has been concern with social work with students and their families, in addition to the more strictly didactic work and, in an ethnographic way, we tried to interpret the point of the subjects listened to. The opening of this group to social activities that are rarely organized within schools has allowed the creation of conditions for a higher education institution to place trainees, both in Social Work and Social Education, to perform social support tasks for students and families and to carry out mediation of a sociocultural and intercultural nature. From the fundamental research carried out in this educational territory and in two others, 10 long open, free and ethnographic interviews were conducted, with two of the teachers being interviewed twice. With these interviews, together with direct and participant observation of various activities carried out both in the classroom and at recess, we sought to understand how different educational and social practices are conceived by different social actors, whether they are potential, emerging or in practice. development.

Indiscipline, single parenting, teenage pregnancy, economic difficulties and, even, the lack of social and parental skills of families are some of the situations that the school struggles with, according to Aldina, a special education teacher at the main school. She adds, also, the existence of a significant number of Roma students, which, according to her, is also a difficult situation to manage due to the "lack of responsibility, attendance and hygiene care". It even says that "this school is a problematic school". This teacher seems to have a unilateral view of the issue that she sees only in the student and in his family the cause of the social problems that come to school.

In an essentially interpretive paradigm and using ethnographic methodologies, as well as individual and group interviews, it was possible to perceive how social workers and social educators are accepted at school, working alongside teachers, putting in practice more mediating social interventions resolutive in the case of social workers, and more transformative and socio-educational in the case of social educators.

\section{RESULTS}

\subsection{The transforming and humanizing role of mediation}

If education should be an instrument to promote equal opportunities and an instrument to favour social justice, school should become a fundamental space to legitimize and strengthen values which structure the State which is, however, nowadays increasingly multicultural. In this sense school has to seek forms of intercultural translation ([8], [9]) as it not only reconstructs cognitive systems but also operates at the level of personal and group identity processes.

Thus, the student's monitoring is assumed as a foundation of training intervention, directed to underprivileged social groups and is translated in the form of mediation between the student, the educational action and the outside; with the family, community, social services, health, etc., in an integrated and student-centred approach.

This monitoring is carried out in a particularly significant way in sociocultural mediation ([10]). In this sense, school plays a fundamental role as a mediating institution, in order to promote not only the access 
and academic success of those students, due to the simplification of the inclusion process there, but also due to the need to seek social inclusion.

By working with the diversities, that is, with other identities, and by seeking ways to help emancipation, mediation has been developed and specialized in various fields, from Legal Sciences, to Management, Psychology, Anthropology, Sociology and transversal themes which are applied to education.

According to Maria Torremorell ([11]), the transforming and humanizing role of mediation should move from the simple proceedings of the judicial process, or an alternative to it, to occupy a central place of a new universal culture. It is an initiated but still very open debate ([1]).

Mediation presumes an advance in the desired social cohesion. It includes the different participants in the conflict, promotes the capacity to understand, accepting the different versions of reality, defends plurality and contributes to the democratic participation, as it fosters free decision-making and commitments. But this process is not automatic. As Torremorell ([12]), states, "[...] we do not assume that the mediation processes alone will build a social bridge for a more humanized future, but that such processes may set one of the stones that will help us cross the river and both ways".

The term "conflict resolution" that is so widespread often leads to the concept of elimination of conflicts. The expression "conflict management", on the other hand, does not intend to end the conflicts (something which is impossible), but rather solve them. Here mediation is seen only as a technique, a tool used in interpersonal relations with complex issues. In fact, in mediation a cultural attitude is combined with a management of techniques. This connection is the key to mediation.

Regarding the presence of the third term "the third" it refers to the mediator as a person, or the team which assumes the role of a bridge, link or catalyst of the mediation processes. The third party presumes and conditions the existence of two parties: "The ternary structure implies openness, given that the third party breaks the duality in which the two beings are involved" ([13]) and it is a common reference point to them.

In relation to the neutrality in mediation, which is one of the most controversial aspects in mediation, when we refer to the mediator, it is true that the mediator has to "maintain a balanced and equidistant position in relation to the protagonists of the conflict, in order to ensure that the process is not flawed nor is it based on preconceptions" ([13]), but it is also true that "nobody should have had the idea of being neutral. There was never neutrality, there never is and there will never be. I believe that the only way of being neutral is being dead" ([13]). Thus, more recently we have gone on to speak about impartiality instead of neutrality, although some authors continue to find such a concept an abstraction. There are also authors that instead of speaking of impartiality - not taking sides - choose to speak about "multipartiality", which is, taking everyone's side. This implies independent and empathetic attitudes from the mediator. However, according to many authors, empathy is not neutral.

According to Capul and Lemay ([14]),

mediation is, therefore, this art of "between two" in which the educator is the privileged intermediary between what has not yet occurred but arises silently and what will come in a series of combined gestures, for having known how to be placed between a strong stimulus and a desired organism to use it.

When defending mediation as a pedagogic, transforming and rehabilitating process, as previously stated, Torremorell ([11]) considers five levels of analysis of the pedagogical value of mediation: 1) mediation with oneself (intrapersonal), which is based on the integral training of the citizen; 2) mediation as a process of promoting coexistence with otherness (interpersonal); 3) mediation as "coefficient of cohesion (intragroup) which refers to communication within the same group or community; 4) mediation as intercommunication among groups (intergroup); 5) mediation as a culture that promotes "cultural competences in order to promote attitudes of openness in relation to other ways of understanding existence or, in other words, the ability to generate empathy with diverse sociocultural meanings and axiological referents" ([15]). Referring to the concept of peace and its reconceptualization, the author emphasizes that "it is no longer considered a passive and unreachable thing but instead it occupies an increasingly important place in everyday life. [...] Replacing the culture of confrontation and litigation with mediation and consensus is in conformity with the ideals of peace, which, unfortunately, materialize too slowly" ([15]).

This is similar to the proposal of Cohen-Emerique ([16]) for whom the particularity of intercultural mediation encompasses the idiosyncrasy of the use of three possible modalities: 1- preventive mediation that seeks to promote the rapprochement, communication and understanding between 
people, groups and communities with different cultural codes; 2 - rehabilitation mediation that intervenes in the regulation and resolution of intercultural tensions and conflicts; 3 - transformative mediation that presumes the opening of a creative process that surpasses norms, customs and particular points of view, in a situation of multicultural coexistence to reach new norms and forms of shared relation, what we have previously designated as learning to coexist, according to Jares ([17]).

Thus, the functions of the intercultural mediator go far beyond the concept of arbitration in contexts of strong multiculturalism and of their conflict resolutions. The intercultural mediator, from our point of view, cannot fail to take part, as we have seen. They cannot be neutral to the point where injustice, violence and inequality are reproduced. On the contrary, they have to be empathic with everyone, enter into everyone's cultural world, and by doing so, they are exactly in the opposite symmetric of assuming a position of neutrality, as we have also seen. Instead, they choose multipartiality because it facilitates communication between people, assists social agents in their relation with the minority, helps people and minority communities, promotes access to public and private services, builds a multicultural citizenship that is able to make intercultural integrations and social integration and empowers and promotes social and community participation.

However, all these functions imply an attitude of social pedagogy ([7]), and a position in search for autonomisation. And, clearly these functions do not only occur in immigration contexts or in work with ethnic minorities. These social functions of the intercultural mediator may be developed in any scope of social intervention, be it educational, social, socio-family, community, legal, labour, environmental, health etc.

In terms of some results and examples of our research about social intervention with intercultural mediation, we observed that Social Workers have, according to our study, more resolving concerns; Social Educators seem to be more concerned with a dialogical, mediating, empowering and preventive intervention and finally, therefore more transformative than properly resolving.

Social workers and social educators, work together in a team where there are also psychologists who recognize that both social workers and educators are better prepared to, for example, make home visits, mediate with families and understand the socio-cultural contexts of students seen at school as undisciplined or as having little interest in the school curriculum.

The teachers and the school principal were also heard and consider that the complexity of the contemporary school, desirably inclusive, cannot be reduced to teachers who teach and students who are supposed to learn.

Teachers and the principal assume they want social workers and social educators at school.

\section{CONCLUSIONS}

In short, we can claim a specific mediation, from an intercultural mediation perspective, for a social intervention with immigrants and ethnocultural minorities, along with other mediations: community, socio-pedagogical, family, legal, labour, among others. But we can also claim a new paradigm of intercultural mediation, transversal to all previous ones, based more on the idea of prevention, transformation, rehabilitation, autonomisation, etc. than on the actual techniques of occasional conflict management/resolution.

It seems to us that, even though we may consider the techniques which are common to general mediation and also to the resolution of tensions and conflicts between ethnocultural differentiated subjects and groups, there should be a stronger particularity of intercultural mediation. Otherwise, why give a new name to a mediation that would ultimately also have the aim of resolving conflicts? Assuredly, we can use the techniques of attentive/active listening; ask appropriate questions so that the parties reformulate [reformulation] their rigid positions; use co-mediation in order to achieve greater effectiveness, etc. But what would be the particularity of the intercultural mediation that would give it its autonomy? Essentially, we believe that it would be the preventive, educational, transformative, enabling and rehabilitating dimension with the view to better communication, a better relation. Ultimately, an intercultural integration [the opposite symmetry of monocultural integration, so close to assimilationism] which fosters the social cohesion and promotes autonomy and social integration of the minorities. 


\section{REFERENCES}

[1] J. A. Caride, Las fronteras de la pedagogia social. Perspectivas científica e histórica. Barcelona: Editorial Gedisa, 2005.

[2] A. N. Peres, "In Memoriam Xesus Jares Rodriguez", in Educação, Justiça e Solidariedade na Construção da Paz (A. N. Peres and R. Vieira, Orgs.), pp. 14-29, Chaves e Leiria: APAP e CIIDIPL, 2010.

[3] T. Aguado and M. Herraz, "Mediación social intercultural en el ámbito socioeducativo", Portularia, vol. VI, no. 1, 2006.

[4] R. I. Arends, Aprender a Ensinar. Lisboa: Editora McGraw-Hill, 1995.

[5] R. Vieira, Educação e Diversidade Cultural: notas de Antropologia da Educação. Porto: Afrontamento e Leiria: CIID-IPL, 2011.

[6] A. Vieira, Educação Social e Mediação Sociocultural. Porto: Profedições, 2013.

[7] A. Vieira and R. Vieira, Pedagogia Social, Mediação Intercultural e (Trans)formações. Porto: Profedições, 2016.

[8] A. Vieira, Histórias de Vida e Identidades, Professores e Interculturalidade. Porto: Edições Afrontamento, 1999.

[9] A. Vieira and R. Vieira, "Pedagogia Social e Mediação Sociopedagógica Como Processos de Emancipação", revista REALIS, vol.4, no. 02, pp. 105-125. Jul-Dez. 2014.

[10] V. Almeida, O Mediador sociocultural em contexto escolar - contributos para a contributos para a compreensão da sua função social. Mangualde: Edições Pedago, 2010.

[11] M. C. B. Torremorell, Cultura de Mediação e Mudança social. Porto Editora, 2008.

[12] See in M. C. B. Torremorell, Cultura de Mediação e Mudança social. Porto Editora, p. 8, 2008.

[13] See in M. C. B. Torremorell, Cultura de Mediação e Mudança social. Porto Editora, p. 23, 2008.

[14] See in M. Capul and M. Lemay, Da educação à intervenção social, vol. I e II. Porto: Porto Editora, p. 113, 2003.

[15] See in See in M. C. B. Torremorell, Cultura de Mediação e Mudança social. Porto Editora, p. 76, 2008.

[16] M. Cohen-Emerique, "La negociación intercultural, fase esencial para la integarción de los inmigrantes", in Hombres y migraciones: todo tipo de mediaciones, Cuaderno de formación, Sevilla: Edit Acoge, 1997.

[17] X. R. Jares, Pedagogia da Convivência. Porto: Profedições, 2007. 